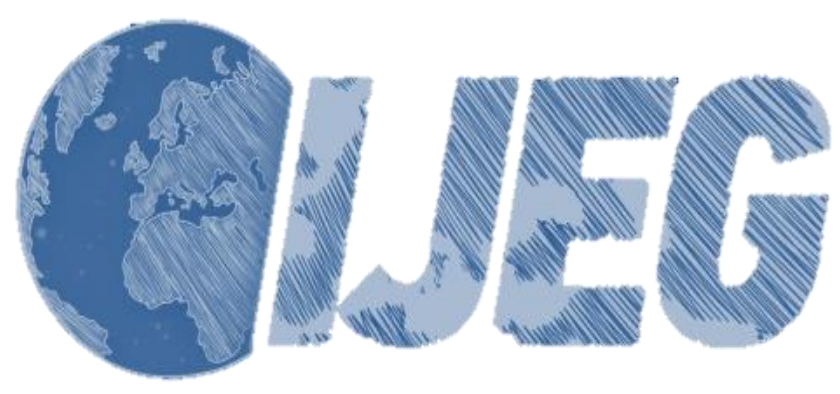

International Journal of Engineering and Geosciences (IJEG), Vol; 4, Issue; 2, pp. 071-077, June, 2019, ISSN 2548-0960, Turkey, DOI: 10.26833/ijeg.450571

\title{
HUMAN RESOURCE MANAGEMENT USING GEOGRAPHIC INFORMATION SYSTEMS (GIS): AN EXAMPLE FROM TURKISH LAND REGISTRY DIRECTORATES
}

\author{
Fred Ernst ${ }^{1 *}$, Saffet Erdoğan ${ }^{1}$, Yüksel Bayram² \\ ${ }^{1}$ Harran University, Engineering Faculty, Department of Geomatics Engineering, Şanlıurfa, Turkey \\ (f.b.ernst/serdogan@harran.edu.tr); \\ ${ }^{2}$ General Directorate of Land Registry and Cadastre, Arsus, Turkey (yukselbayram73@hotmail.com)
}

ORCID 0000-0002-7568-2582; ORCID 0000-0003-2846-853X; ORCID 0000-0001-7686-8648;

*Corresponding Author, Received: 03/08/2018, Accepted: 23/10/2018

\begin{abstract}
Recently, a new interest in the social science community in location and a new "spatial social science" that crosses the traditional boundaries between disciplines have emerged. In this context, we will examine the usage of Geographic Information Systems (GIS) in the analysis of human resource management in the public sector. For this research, personnel and operational data of 957 Land Registry Offices in all districts of Turkey were used. These operational data were examined using different clustering techniques. By using tools of Geographic Information Systems to analyze public services, the distribution and condition of services can be understood much better. This study shows the first step to improve them and to allow for making better-informed decisions on where, when and what kind of resources to allocate in the human resource management in the public sector.
\end{abstract}

Keywords: Clustering, GIS, human resource management, spatial analysis 


\section{INTRODUCTION}

Until recently, for many social scientists, location was just another attribute in a table and not a very important one at that. This was based on the assumption that processes leading to social deprivation, crime, or family dysfunction are more or less the same everywhere. According to this belief, many other variables, such as education, unemployment, or age, are far more interesting as explanatory factors of social phenomena than geographic location.

Those who believe in such a paradigm forget that even in the 18th century the well-known economist Adam Smith addressed in his book "The wealth of nations" the issue that the physical geography of a region can influence its economic performance. For example, he contended that the economies of coastal regions, with their easy access to sea trade, usually outperform the economies of inland areas.

However, when Sachs et al. (2001) were trying to answer the similar question "Why are some countries stupendously rich and others horrendously poor?" they used Geographic Information Systems (GIS). Tomlinson who is called the "father of GIS" (Tomlinson et al. 1999, Tomlinson, 2011) defined GIS as a system that stores spatial data replete with its linked logically attribute information, in a GIS storage database, where analytical functions are controlled interactively by a human operator to generate the needed information products. GIS is a particularly horizontal technology in the sense that it has wide-ranging applications across the industrial and intellectual landscape.

As Michael Goodchild outlined in his essay "Social Sciences: Interest in GIS grows" (Goodchild, 2004), many social scientists have started to talk about a "spatial turn," which refers to the importance of location, and a new "spatial social science" that spans the traditional boundaries between disciplines. As a result, rising interest in GIS and what it makes possible: (mapping, spatial analysis, and spatial modeling) can be noticed. For example, in criminology, geographic profiling has been used for about 20 years (Harries et al., 1999). This tool for fighting crime makes use of the principle of distance decay, which is applied to the behavior of the offender and the locations of a series of crimes that show the same used methods. GIS generates distance decay surfaces centered on each crime and superimposes it to create a three-dimensional surface that likely peaks in the criminal's home area.

Especially, different kinds of clustering techniques have been proven to be useful in the analysis of complex and extensive socio-economic data (big data). According to Jan et al. (1999) clustering can be defined as "the unsupervised classification of patterns (observations, data items, or feature vectors) into groups (clusters)".

The usage of Empirical Bayes smoothing approach is very common in population related studies. For example, Sparks et al. (2013) used this approach to the study of racial and poverty segregation and infant mortality rates in the US. They used both Exploratory Spatial Data Analysis methods and Hierarchical Bayesian spatial regression models to examine the influences of these segregation measures on the infant mortality rate for each county, net of income inequality, degree of rurality and relative socio-economic deprivation. Their spatial analysis of racial segregation suggested that when blacks live in close proximity to each other, this tends to increase the infant mortality rate.

Moran's I index has been widely adopted in the GIS community and has become part of many GIS software packages. It is explained in detail in the standard GIS textbook "The ESRI Guide to GIS Analysis" (Mitchell, 2005) where some applications in the field of population science are given as well.

The Getis-Ord $\mathrm{G}^{*}$ index was introduced by Getis et al. (1992) in 1992 and has become a standard tool for spatial statistics. The empirical work in their article included studies of sudden infant death syndrome by counties in North Carolina and dwelling unit prices in metropolitan San Diego by zip-code districts. Their results indicated that the Getis-Ord $G^{*}$ index should be used in conjunction with Moran's I index in order to identify characteristics of patterns not revealed by the Moran's I index alone.

Recently, many local governments have responded to the challenge of decreasing budgets by instituting performance management systems for their departments (Oliver 2005). Such systems enable governments to make decisions based on sound financial analysis and to target their limited resources toward productive programs. The systems gather various performance data as indicators of effectiveness and use trend analysis to inform officials and managers who allocate resources and make decisions. In addition, these systems can determine if programs are achieving the desired results and meeting the needs of the public.

In a recent research (İşcan et al. 2017), web sites of local governments in Turkey have been evaluated regarding city guides and applications for e-municipality. They stated that GIS is used by municipalities to provide better services and to improve decision making mechanisms including tax administration and city planning.

\subsection{GIS for Human Resource Management as a new application in Turkey}

In Turkey, GIS based studies are generally related to urban management applications (Çabuk, 2015), health applications (Demirel et al., 2009), traffic applications (Erdoğan, 2009), infrastructure applications (Furat et al. 2015), criminology applications (Erdoğan, 2013) and environmental research applications (Ernst, 1996). In the areas of social sciences and public service management, GIS applications are hardly used. Among these few studies Türk (2011) can be mentioned. He investigated the distribution of crimes in Turkey using GIS. He concluded that GIS based analysis might help to analyze existing social problems in Turkey and to provide criminologists and sociologists with new tools to tackle these problems.

In the domain of public service management, GIS can be utilized to visualize the geographic distribution of public services, to investigate the statistical increase or decrease in these services, to analyze and map ratios and trends in public service performance, and to locate problematic areas. GIS can also be deployed for temporal, spatial or time-space integrated clustering studies based on various sets of criteria. Within the scope of public management, human resource management refers to the complete set of human resources employed as public officials and employees providing public services for the 
community in state institutions and organizations. The concept of human resource management in public services can be examined under three main components: human resource planning, better employment of human resources and developing the efficiency and effectiveness of human resources by providing effective training (onsite or distance learning) (Yuluğ, 1971).

Human resource management is the main part of three components and is defined as employing an adequate number of highly-qualified public personnel with a proper distribution and appropriate timing with the aim of performing the provided and projected social services. In addition, human resource planning can be defined as predicting the short, medium and long-term needs of society and as considering the ratio between geographic, economic and socio-cultural features and providing a cost-effective public service. It covers the employment, management, and planning of the most fitting human resources for the public service. Human resource planning entails two key objectives, the first is enabling the most effective use of human resources in public institutions and the second is meeting the human resource needs of the institution in terms of both quantity and quality for future operations. The reasons necessitating human resource planning in public institutions are; the cost of human resources, social and political changes, advancements in science and technology, the inadequacy of public personnel with respect to quantity and quality, and the rapid increase of digital data (Dikmetaş et al., 2000).

The applicability and validity of planning necessitate not only the accessing of correct information at the correct time but also the utilization of the best-tailored analysis techniques. Therefore, the purpose of the present study is to detect underload and overload of human resources within the General Directorate of Land Registry and Cadastre-Turkey (TKGM) by applying different GIS based spatial analyses. For this, we have examined the total number of annual title transactions executed in its 957 Land Registry Offices that operate and provide public services. In addition, we examined the total number of personnel employed in the directorates of the land registry.

\section{DATA AND METHODOLOGY}

In this study, we collected figures for the total number of sales, nationalization, evacuation, incorporating, public works, donation, hypothecation, land use conversion, property ownership identification, construction servitude identification, and lifelong support agreement works received from baye for the period from 2013 to 2014 on the basis of land directorates within each single city and town (TSM). Other data include the number of personnel received from TSMs.

GIS based visualization of the geographic distribution of public services is a method that is useful in detecting the density of served areas. Visualization is the first stage of GIS analysis and a number of social and academic GIS studies in Turkey provide research information about this stage. In the second stage, using several exploratorydescriptive spatial statistical tools of GIS, it is possible to provide a statistics-assisted description of the current situation in public services and a description of the sectoral problems. Spatial analyses used at this stage can be categorized into two different groups: first order and second order analyses.

First order analyses investigate spatial changes in the data whilst second order analyses spatial covariance between the data. Thus, first order analyses aim to detect data changes in density analysis, spatial ratio analysis etc. and global and regional trends and outliers and second order analyses aim to estimate spatial dependency and changes in spatial dependency between the data. In the complete set of first and second order analyses, the aim is to better understand data structure and the spatial distribution of the data by computing various descriptive statistical indices. By detecting temporal and spatial clustering of the data, priority action areas are detected and confirmed. Exploratory/descriptive spatial statistical methods used at this stage are vital to the detection of the structure and distribution of public service-relevant data; their interactions with the environment; areas in which the services defined as hot or cold points are located and their density.

Although these methods are effective in detecting the outliers and trends in spatial data and various sets of clustering, they still fail to explain the underlying mechanisms of clustering. In the spatial modelling process, which is the third step in GIS assisted analyses, modelling studies are conducted on the basis of several explanatory independent variables and their spatial distribution. Using such spatial modelling methods, hypotheses related to the case study and factors affecting the distribution of a particular case can also be tested on the basis of spatial relations (Demirel et al., 2009)

GIS is a frequently applied method that is useful in detecting area density with respect to certain criteria and to visualize the geographic distribution of public services. In order to provide visual information, thematic maps that display personnel distribution in Land Registry Directorates and population/personnel ratio are devised in the first stage (Figure 1).

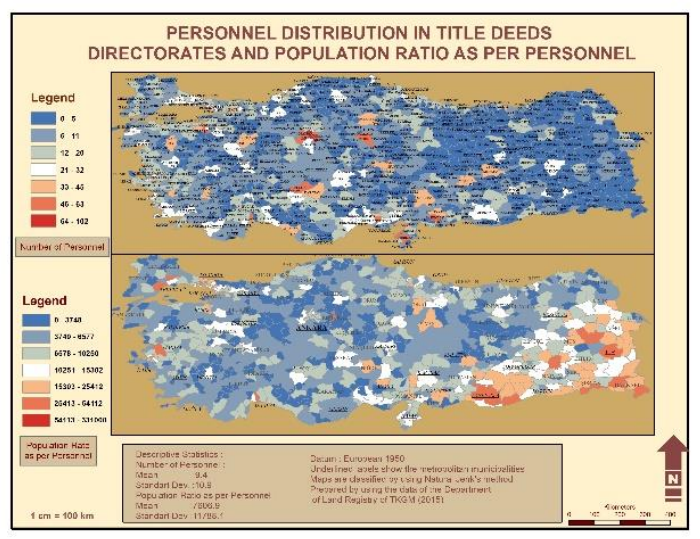

Figure 1: Personnel distribution in Land Directorates and population/personnel ratio. 
International Journal of Engineering and Geosciences (IJEG),

Vol; 4, Issue; 2, pp. 071-077, June, 2019,
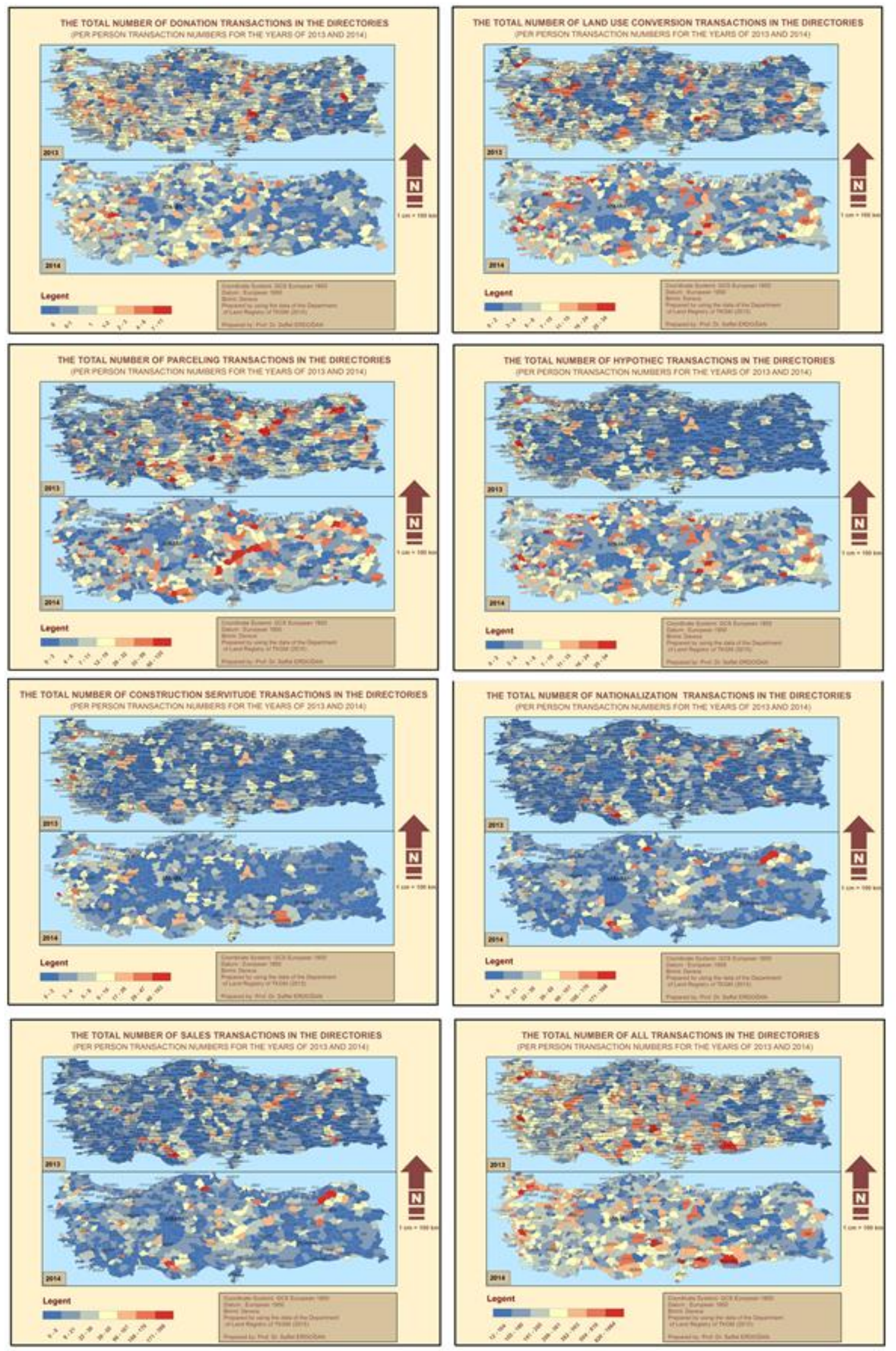

Figure 2: Per person transaction numbers in land registry directorates with EB smoothed values. 
If the excess risk value, which is obtained by rationing the actual number of cases by the estimated number of cases, equals one it means there is no difference between exposure and risk; if the value is above one there is an increased risk and if its below one there is a decreased risk. Hence, the structured excess risk maps are created by rationing the total number of actualized transactions performed in the land directorates by the ratio of estimated transaction numbers. Land directorates with values above one mean it is higher than the mean risk values with respect to the actualized transaction number; so they are problematic directorates in terms of transaction capacity (Figure 3 ).

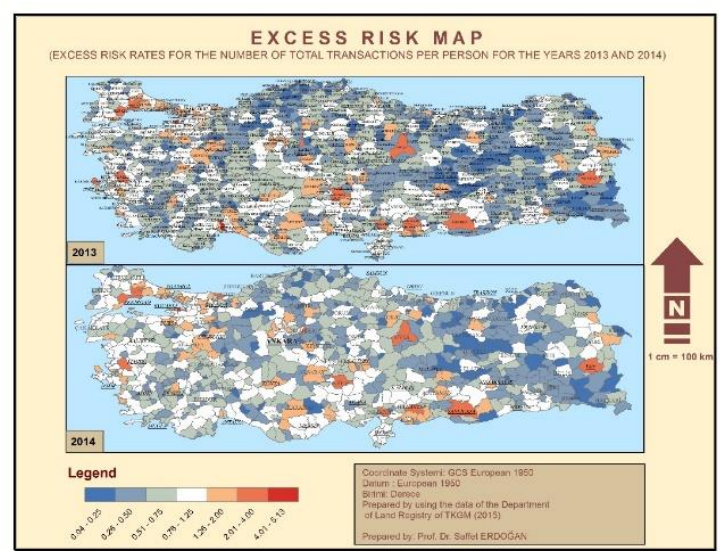

Figure 3: Excess risk map with respect to TSM transaction numbers.

Another spatial analysis performed using the ratios is spatial rate analysis, which is based on spatial moving areas. Instead of using independently estimated ratios for each TSM unit in a zone town, spatial rate analysis uses the mean value of ratios from other neighbors defined via neighborhood relations and determined with a weight matrix for each unit. In this analysis, depending on the number of identified neighbors, the values of units with high and low ratios are drawn closer to the neighborhood mean value by using neighbor values with the aim of determining regional and global changes. The critical issue here is the number of neighbors, as the number of neighbors is increased the raw ratio values become similar for the neighbor towns and once all neighbors are selected, the values of all towns become exactly the same (Anselin et al., 2006).

$$
\pi=\frac{E_{i}+\sum_{j=1}^{j_{i} E_{j}}}{P_{i}+\sum_{j=1}^{j_{i}} P_{j}}
$$

The results of spatial rate analysis conducted to visualize the regional and global changes in the number of actualized transactions in TSMs are shown in Figure 4.

In the next stage, based on the spatial dependency in a TSM zone defined by official territories, clustering sets were determined in terms of transaction numbers and per person transaction numbers and spatial auto-correlation, analyses were conducted.

In our study, after several tests, a weight matrix is formed by using the features of the seven closest neighborhoods, and Moran's I and Getis-Ord G* spatial auto-correlation methods were employed (Getis et al., 1992) (Moran, 1948)

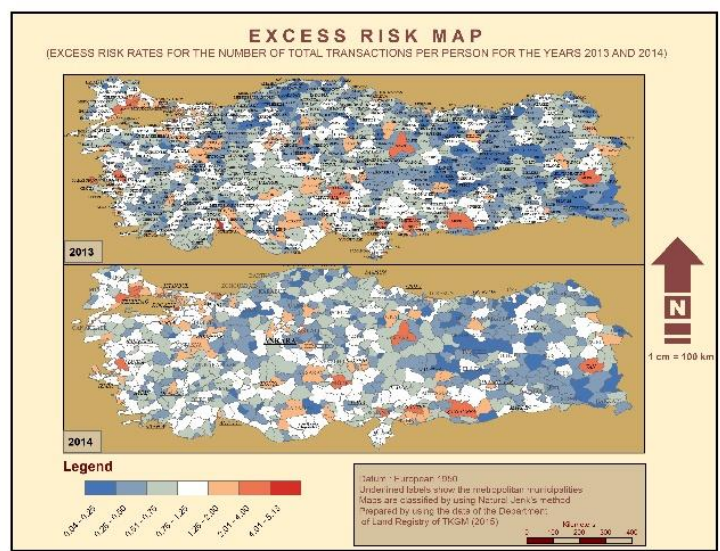

Figure 4: Regional changes and trends by spatial rate map with respect to the number of actualized transactions in TSMs.

The values that Moran's I spatial auto-correlation take vary between -1 and +1 . Positive values indicate spatial clustering of the identical objects defined as hot or cold spots whilst negative values show the clustering of different objects defined as outlier points (4).

$$
I_{i}=\frac{\left(X_{i}-\bar{X}\right)}{S^{2}} \sum_{j} W_{i j}\left(X_{j}-X\right)
$$

Although Moran's I index can produce the clustering of high and low values of objects, it fails to distinguish the objects from each other. This was expressed by Anselin (1995) who made some adaptations to Moran's I index and provided the LISA (local indicators of spatial association) index, which can produce a local-based clustering analysis. In LISA, statistically significant local clustering results are identified in four different categories as high-high, high-low, low-high, low-low. The TSM-related map produced by using LISA with respect to transaction numbers per person is shown in Figure 5.

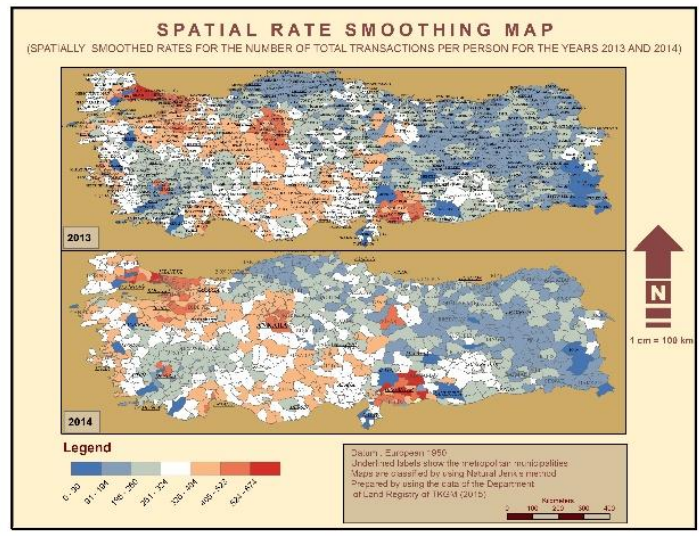

Figure 5: Transaction numbers per person using Moran's I clustering analysis. 
In the final stage of this analysis, a different spatial auto-correlation index, known as the Getis-Ord G* index, was used to compare the results. Unlike Moran's I index, Getis-Ord $\mathrm{G}^{*}$ index is more sensitive in determining to cluster in high values. The positive values of Getis-Ord $\mathrm{G}^{*}$ index take to mean the clustering of high-value objects, negative values mean the clustering of low-value objects and null value indicates randomness in the distribution of objects. The Getis-Ord $\mathrm{G}^{*}$ index is generically used to compliment Moran's I index results and its formulation is as provided below. In Figure 6, the TSM-related map using clusters using based on the GetisOrd $\mathrm{G}^{*}$ index with respect to transaction numbers per person can be viewed.

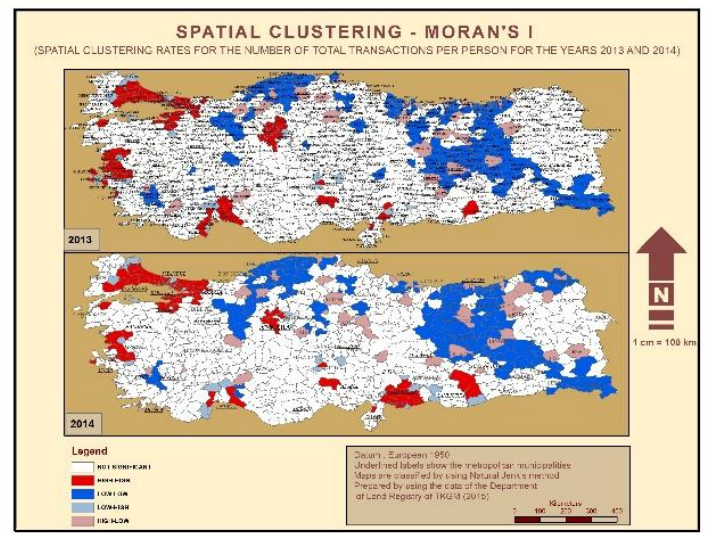

Figure 6: Transaction numbers per person using the GetisOrd $\mathrm{G}$ clustering analysis

\section{CONCLUSION AND DISCUSSION}

In this study, GIS based spatial analyses have been exploited for human resource planning and employment relevant analysis in TSM. From the population figures and distribution per employee and as per a total number of employee volumes, there are approximately nine employees (standard deviation 10) in the directorates. The geographic distribution of directorates as per a number of total personnel shows that there is a homogeneous distribution. However, the standard deviation value of the number of personnel is higher since there exist many directorates whose values differ strongly from the mean values. Analysis of the geographic distribution of directorates with higher than average numbers of personnel shows that these directorates are mostly centered in metropolitan cities and central and western Anatolia. With respect to serviced population per person, it is detected that directorates located in the South East Anatolian Region and a few of the Metropolitan directorates are problematic (Figure 1). As the number of transactions per person is investigated it is seen that aside from the metropolitan directorates with high transaction volumes, there are density indicators in certain urban directorates (Kars, Nigde, Aksaray, Osmaniye, Tokat) (Figure 2). When the excess risk ratio of directorates with respect to work load is examined (Figure 3 ) it is seen that Yalova, Aksu, Cerkezköy, Bahcelievler, Corlu, Manisa, Osmaniye, Nigde, Gaziantep, Şanlıurfa, Sivas, Karaburun directorates have risk values six times above the mean risk value with respect to transaction numbers per person. When the results of spatial rate analysis conducted to understand regional and national changes in the number of transactions conducted per person in TSMs are examined it shows that directorates in İstanbul, Ankara, Gaziantep, Şanlıurfa cities are inclined towards an upper curve on a nationwide scale whilst the East of Turkey, including the complete territory of the Black Sea Region, is inclined towards a downward curve (Figure 4). In the present study, Moran's I and Getis-Ord G spatial analysis methods were employed to determine clustering sets of directorates that exhibit identical features. As the results of these analyses are examined, it is seen that both methods detected identical geographical regions.

Due to geographic, economic and cultural differences in Turkey's regions, a number of variations in the distribution of public services have been identified. GIS is a useful tool for making sound decisions by making the best usage of all available resources at global, national and regional scales with the aim of solving a wide range of problems, providing services, and managing both human and physical resources. The first stage for using GIS for public services is the visualization of statistics by means of appropriate mapping methods and thereby, enabling decision-making managers to make fast, accurate and effective decisions. In the second stage, a number of spatial statistical tests are conducted and according to the obtained results, directories exposing deficiencies can be determined with statistical significance.

The management and supervision of public services constitute a vital task for governments, public institutions, and organizations. By using GIS applications to analyse public services, it becomes easier to understand the distribution and condition of services in order to improve them and it is possible to make more effective decisions on where, when and what kind of resources to allocate. The present study is the first GIS based research in Turkey providing in-depth analysis of public human resource in Land Registry Directories within the scope of management and supervision of public services.

The application of GIS technology proves to be invaluable because it offers advanced analysis capabilities including the study of time series and overlay with additional spatial data layers like income, population composition and density, unemployment, literacy, etc. This can help to get insight into patterns of social and economic relationships that otherwise would have been left undetected.

\section{REFERENCES}

Anselin, L. (1995). Local 1ndicators Of Spatial Association-LISA. Geographical Analysis, 27, pp. 93115.

Anselin, L., Lozano, L., Koschinsky, J. (2006). Rate Transformations and Smoothing. Spatial Analysis Laboratory Department of Geography, University Of Illinois. Urbana-Champaign. 
Çabuk, S.N. (2015). GIS Use in Local Authorities and Urban Information Systems. Electronic Journal of Map Technologies. 7, 3, pp. 69-87.

Demirel, R., Erdoğan, S., Sözen, M. A. (2009). Determination of High Risk Regions of Human Brucellosis in Turkey Using Exploratory Spatial Analysis. Turkiye Klinikleri J Med Sci, 29, 1, pp. 25-35.

Dikmetaş, E.; İnan, N. (2000). Sağlık İnsan gücü Planlaması. 1. Ulusal Sağlık İdaresi Kongre Kitabı, Ankara, pp. 107-117.

Erdoğan, S. (2009). Explorative Spatial Analysis of Traffic Accident Statistics and Road Mortality among the Provinces of Turkey. Journal of Safety Research, 40, 5, pp. 341-355.

Erdoğan, S.; Yalçın, M.; Dereli, M.A. (2013.) Exploratory spatial analysis of crimes against property in Turkey. Crime Law Social Change, 59, 1, pp. 63-78.

Ernst, F. (1996). Erstellung eines digitalen Umweltatlas für die Provinz Adana (Südtürkei) (A digital environmental atlas for the Province of Adana (southern Turkey)). Petermanns Geographische Mitteilungen. 140 (4): 217-226.

Firat, M.; Dursun, Ö. F.; İnce, K.; Talu, M. F.; Aydoğdu, M. (2015). Coğrafi Bilgi Sistemlerin Kentsel Alt Yap1 Sistemlerinde Kullanılması. ADYU Mühendislik Bilimleri Dergisi, 2, pp. 24-33.

Getis, A.; Ord, J. K. (1992). The Analysis of Spatial Association By Use Of Distance Statistics. Geographical Analysis, 24, 11, pp. 189-206.

Goodchild, M. (2004). Social Sciences: Interest in GIS Grows. ArcNews Online. Spring 2004. URL: http://www.esri.com/news/arcnews/spring04articles/soci al-sciences.html

Harries, K. (1999). Mapping Crime: Principle and Practice. Department of Justice. Washington, D.C.

İşcan, F., Ilgaz, A. (2017). Analysis of Geographic/Urban Information System Web Presentations of Local Goverments In Turkey, International Journal of Engineering and Geosciences, 2, 3, pp. 75-83.
Jan, A.K., Murty, M.N., Flynn, P.J. (1999). Data Clustering: A Review, ACM Computing Surveys, Vol. 31, No. 3, pp. 263-323.

Mitchell, A. (2005). The ESRI Guide to GIS Analysis. Volume 2: Spatial Measurements and Statistics. ESRI Press, Redlands, California.

Moran, P. A. P. (1948). The interpretation of statistical maps. Journal of the Royal Statistical Society Series B10,36 .

Oliver, D. R. (2005). Internal business functions. The GIS Guide for Local Government Officials. Redlands, CA: ESRI Press, pp. 61-79.

Sachs, J. D.; Mellinger, A. D., Gallup, J. L. (2001) The Geography of Poverty and Wealth. Scientific American. URL:http://www.joyhecht.net/East\%20Africa\%20Clima te $\% 20$ Change/Sachs\%20geography $\% 20$ of $\% 20$ povery $\%$ 20\&\%20wealth\%20SciAm\%202001.pdf

Sparks, P.J, Corey S. Sparks, Joseph J. A. Campbell (2013). An application of Bayesian spatial statistical methods to the study of racial and poverty segregation and infant mortality rates in the US. GeoJournal, 78:389405.

Tomlinson, R. F., Toorney, M.A.G. (1999). GIS and LIS in Canada. In: McGrath, G., Sebert, L. (eds.), Mapping a Northern Land: The Survey of Canada 1947-1994, McGill-Queen's University Press, Montreal, Quebec, Canada.

Tomlinson, R. F. (2011). Thinking About GIS: geographic information system planning for managers (4th ed.). ESRI Press. Redlands, CA.

Türk, T. (2011). Türkiye'de Meydana Gelen Suçların Coğrafi Bilgi Sistemleri (CBS) ile İncelenmesi, hkm Jeodezi, Jeoinformasyon ve Arazi Yönetimi Dergisi, 1, 104, pp. 14-20.

Yuluğ, M. (1971). Kamu Kesiminde İstihdam Sorunu ve Yeni Personel Rejimi. Amme İdaresi Dergisi 4, 2, 46-51. 